\title{
The challenge of maintaining doctoral student well-being during Covid-19 confinement
}

\author{
Abdelhafid Jabri \\ Mohammed First University, Oujda, Morocco
}

Keywords: confinement; creative writing; doctoral supervision; online feedback; psychological well-being; Covid-19.

\section{The challenge}

As is widely known, doctoral students notoriously rely on their relationship with their supervisors, as it is not only an academic but also a human relationship. Ives and Rowley (2005, cited Mainhard et al., 2009, p.360) confirm that good interpersonal relationships between supervisors and supervisees have a positive impact on the research progress, on student satisfaction, and on the quality of academic feedback. The latter is a significant factor in the student's success especially when it is 'specific, timely, positive [...] and tailored to the student' (Petty, 2009; Paolini, 2015; Wiltbank et al., 2019, cited Anastasiadis and O'Brien, 2019, p.6). In sum, whether doctoral feedback is exclusively in-person (faceto-face) or hybrid (both face-to-face and online), it is a key factor in the success of doctoral students, and of the higher educational system in general, because it might provide useful lessons to foster supervisor/supervisee relationships (Conn et al., 2009; Hast, 2017).

However, complete reliance on asynchronous online communication with my supervisor during the confinement period led to moments of confusion. With the confinement measures taken in 2020 following the emergence of the Covid-19 pandemic, the procedure for doctoral students at my university was initially to gain feedback via email. This had advantages like time reduction, cost-effectiveness and easy access to information, yet it was difficult for both supervisors and supervisees due to the decreased quality of communication. In this respect, several studies confirm that technology-based supervision contributes to a decrease in supervisor-student bonding (Conn et al., 2009). Likewise, Oh et al. (2008, cited Roberts and Wasieleski, 2012) attest that technology, 
especially when used in asynchronous ways, increases students' feelings of social distance. In the absence of face-to-face interaction, I felt confused, as I could not adequately fathom my supervisor's overall satisfaction with my progress only through email. This confusion led to feelings of loneliness and helplessness. Likewise, one of my colleagues underwent the same difficult experience, as he confessed to me that getting face-to-face feedback from his supervisor was much better than getting it via email. With the former he could easily grasp the supervisor's expectations and degree of satisfaction; with the latter, he also felt confused and lonely. Such negative feelings amplified the risk of having poor psychological well-being and failure in one's academic goals. In this regard, research confirms that 'poor mental wellbeing can lead to poor productivity and lower levels of commitment to research' (Guthrie et al., 2017, cited Buckley et al., 2021, p.3). Therefore, the challenge, for both of us, was how to look after our well-being in the face of stress caused by physical distancing added to the other doctoral pressures listed by Buckley et al. (2021).

\section{The response}

Aware that any doctoral student is a learner who needs to manage, among other challenges, the psychological challenge inherent in any doctoral journey (Cantwell et al., 2015, cited Devos et al., 2017), I took two major steps. Firstly, reaching out to my supervisor was greatly helpful. Once we established contact through instantaneous forms of communication (such as phone calls and WhatsApp), I became clear-headed about her satisfaction with my progress. To hear her reassuring voice made a big difference in boosting my motivation because its tone communicated her impression and expectations clearly. Likewise, exploiting occasional face-to-face academic meetings to exchange our reflections on my research upon deconfinement was equally fundamental to staying on track thanks to verbal and nonverbal communication. In short, prompted by the challenge of looking after my well-being and staying on track in the face of physical distancing barriers, I looked for opportunities to make the most of other avenues of communication.

Secondly, I sought creative outlets to keep my spirits high. In this regard, creative writing was soothing to me because it was energising and mind-clearing. Having a poem published in an American peer-reviewed literary magazine and winning a university poetry 
contest helped me overcome the negative emotions caused by overreliance on online asynchronous feedback. In the same vein, organising an online dual poetry event with my aforementioned colleague made room to create a positive state of mind. This is supported by studies which have pointed to the positive effects of poetry writing on psychological well-being. For instance, Croom (2014) reports that, for patients with serious psychological issues, 'engaging in the practice of poetry can positively contribute to one flourishing with greater psychological well-being' (p.3). In other words, because positive emotions affect well-being (Fredrickson, 2006; Robinson and Von Hippel, 2006; Vallerand, 2012, cited in Croom, 2014), and because practising poetry creates positive emotions in doctoral students by relieving their stress, promoting self-understanding and filling feelings of emptiness (Chan, 2003, cited Croom, 2014), practising poetry contributes to psychological well-being (Croom, 2014). To sum up, in addition to other avenues of communication when necessary, writing poetry contributed remarkably to maintaining my psychological wellness during the confinement period.

\section{Recommendations}

The following recommendations might guarantee successful maintenance of psychological well-being on the doctoral journey during periods of crisis. To begin with, doctoral students and their supervisors should prioritise face-to-face meetings. In-person meetings are crucial because they spare supervisees' unnecessary negative feelings associated with the exclusive use of asynchronous ways. But when online feedback is the only solution, it should be both asynchronous (via email) and synchronous (through video and audio meetings). In this light, increasing the quality of supervisory interaction by seeking new ways to communicate feedback is highly important, as confirmed by a study by Devos et al. which revealed that doctoral students are part of a more complex network of interactions and that the quality of this interaction 'help[s] them cope in case of difficulties' (2017, p.67). Next, seeking creative outlets such as poetry writing when stressed or in distress may positively enhance the well-being of doctoral students, as it may shift their focus from negative ideas to positive ones. The beauty of poetic language, the musicality of poetic recitation, and the sense of accomplishment from creative writing may positively affect their temper. However, in addition to these recommendations, doctoral students need to take into account other considerations. As Devos et al. (2017) highlight, whether 
their doctoral topics are interesting to them (that is, whether they make sense to them), and whether they already have some earlier counterproductive habits such as procrastination and perfectionism, highly determine their decision to complete or quit a doctoral program (p.68). Therefore, doctoral students should keep in mind not only the nature of supervisory communication and the role of creative outlets, but also their interest in the topic and their counter-productive habits. With this mentality, they will undoubtedly increase their well-being and their ability to cope with other significant challenges during periods of crisis.

\section{References}

Anastasiadis, S. and O'Brien, J. (2019) 'An exploration of taught master's student perceptions of UK dissertation supervision', Journal of Learning Development in Higher Education, 0(16), pp.1-38. Available at: https://doi.org/10.47408/ildhe.v0i16.490 (Accessed: 1 October 2021).

Buckley, C., Saetnan, E., Gerber, A., Cheetham, J., Price, T., Kenyani, J. and Greaves, A. (2021) 'Impact of writing workshops on doctoral student wellness', Journal of Learning Development in Higher Education, (20), pp.1-24. Available at: https://doi.org/10.47408/jldhe.vi20.593 (Accessed: 1 October 2021).

Conn, S.R., Roberts, R.L. and Powell, B.M. (2009) 'Attitudes and satisfaction with a hybrid model of counselling supervision', Journal of Educational Technology \& Society, 12(2), pp. 298-306. Available at: https://www.jstor.org/stable/jeductechsoci.12.2.298 (Accessed: 1 October 2021).

Croom, A.M. (2014) 'The practice of poetry and the psychology of wellbeing', Journal of Poetry Therapy, 28(1), pp.21-41. Available at: https://doi.org/10.1080/08893675.2015.980133 (Accessed: 1 October 2021).

Devos, C., Boudrenghien, G., Van der Linden, N., Azzi, A., Frenay, M., Galand, B. and Klein, O. (2017) 'Doctoral students' experiences leading to completion or attrition: a matter of sense, progress and distress', European Journal of Psychology of 
Education, 32(1), pp.61-77. Available at: https://doi.org/10.1007/s10212-016-0290-0 (Accessed: 1 October 2021).

Hast, M. (2017) 'Supporting student transition to higher education feedback: an evaluation of an online feedback training approach', Journal of Learning Development in Higher Education, 0(12), pp.1-15. Available at: https://doi.org/10.47408/jldhe.v0i12.438 (Accessed: 1 October 2021).

Mainhard, T., Van der Rijst, R., Van Tartwijk, J. and Wubbels, T. (2009) 'A model for the supervisor-doctoral student relationship', Journal of Higher Education, 58(3), pp.359-373, Available at: https://doi.org/10.1007/s10734-009-9199-8 (Accessed: 1 October 2021).

Roberts, J.A. and Wasieleski, D.M. (2012) 'Moral reasoning in computer-based task environments: exploring the interplay between cognitive and technological factors on individuals' propensity to break rules', Journal of Business Ethics, 110(3), pp. 355-376. Available at: https://doi.org/10.1007/s10551-011-1196-z (Accessed: 1 October 2021).

\section{Author details}

Abdelhafid Jabri is a doctoral student in the Faculty of Letters, Humanities and Arts at Mohammed First University, Oujda, Morocco. His research interests centre on moral and environmental philosophy in fiction but also on their applications in higher education. 